\title{
A DNA and morphology based phylogenetic framework of the ant genus Lasius with hypotheses for the evolution of social parasitism and fungiculture
}

\author{
Munetoshi Maruyama ${ }^{\dagger 1,2}$, Florian M Steiner*†3,4,5, Christian Stauffer ${ }^{4}$, \\ Toshiharu Akino ${ }^{6}$, Ross H Crozier ${ }^{5}$ and Birgit C Schlick-Steiner ${ }^{3,4,5}$
}

\begin{abstract}
Address: ${ }^{1}$ Department of Zoology, National Science Museum, Hyakunin-chô 3-23-1, Shinjuku-ku, Tokyo 169-0073, Japan, ${ }^{2}$ Department of Zoology, Field Musem of Natural History, 1400 South Lake Shore Drive, Chicago IL 60605-2496, USA, ${ }^{3}$ Institute of Zoology, Department of Integrative Biology and Biodiversity Research, Boku, University of Natural Resources and Applied Life Sciences Vienna, 1180 Vienna, Austria, ${ }^{4}$ Institute of Forest Entomology, Forest Pathology and Forest Protection, Department of Forest and Soil Sciences, Boku, University of Natural Resources and Applied Life Sciences Vienna, 1190 Vienna, Austria, ${ }^{5}$ School of Marine and Tropical Biology, James Cook University, Townsville, Queensland 4811, Australia and 'Laboratory of Insect Behavior, National Institute of Agrobiological Sciences, Ôwasi 1-2, Tsukuba-shi 305-8634, Japan
\end{abstract}

Email: Munetoshi Maruyama - dorylus@hotmail.com; Florian M Steiner* - birgit.florian@gmail.com;

Christian Stauffer - christian.stauffer@boku.ac.at; Toshiharu Akino - t-akino@kit.ac.jp; Ross H Crozier - ross.crozier@jcu.edu.au; Birgit C Schlick-Steiner - birgit.florian@gmail.com

* Corresponding author †Equal contributors

Published: 19 August 2008

BMC Evolutionary Biology 2008, 8:237 doi:10.1 186/147/-2/48-8-237
Received: 18 December 2007

Accepted: 19 August 2008

This article is available from: http://www.biomedcentral.com/I47I-2| 48/8/237

(C) 2008 Maruyama et al; licensee BioMed Central Ltd.

This is an Open Access article distributed under the terms of the Creative Commons Attribution License (http://creativecommons.org/licenses/by/2.0), which permits unrestricted use, distribution, and reproduction in any medium, provided the original work is properly cited.

\begin{abstract}
Background: Ants of the genus Lasius are ecologically important and an important system for evolutionary research. Progress in evolutionary research has been hindered by the lack of a wellfounded phylogeny of the subgenera, with three previous attempts disagreeing. Here we employed two mitochondrial genes (cytochrome c oxidase subunit l, I6S ribosomal RNA), comprising I,265 bp, together with 64 morphological characters, to recover the phylogeny of Lasius by Bayesian and Maximum Parsimony inference after exploration of potential causes of phylogenetic distortion. We use the resulting framework to infer evolutionary pathways for social parasitism and fungiculture.
\end{abstract}

Results: We recovered two well supported major lineages. One includes Acanthomyops, Austrolasius, Chthonolasius, and Lasius pallitarsis, which we confirm to represent a seventh subgenus, the other clade contains Dendrolasius, and Lasius sensu stricto. The subgenus Cautolasius, displaying neither social parasitism nor fungiculture, probably belongs to the second clade, but its phylogenetic position is not resolved at the cutoff values of node support we apply. Possible causes for previous problems with reconstructing the Lasius phylogeny include use of other reconstruction techniques, possibly more prone to instabilities in some instances, and the inclusion of phylogenetically distorting characters.

Conclusion: By establishing an updated phylogenetic framework, our study provides the basis for a later formal taxonomic revision of subgenera and for studying the evolution of various ecologically and sociobiologically relevant traits of Lasius, although there is need for future studies to include nuclear genes and additional samples from the Nearctic. Both social parasitism and fungiculture evolved twice in Lasius, once in each major lineage, which opens up new opportunities for comparative analyses. The repeated evolution of social parasitism has been established for other 
groups of ants, though not for temporary social parasitism as found in Lasius. For fungiculture, the independent emergence twice in a monophyletic group marks a novel scenario in ants. We present alternative hypotheses for the evolution of both traits, with one of each involving loss of the trait. Though less likely for both traits than later evolution without reversal, we consider reversal as sufficiently plausible to merit independent testing.

\section{Background}

Ants of the Northern-hemispheric, temperate genus Lasius (Formicinae) are scientifically significant, in terms of relative abundance and ecological impact [1,2]. Because of the diversity of their signal and defense chemistry, Lasius ants are organisms widely used in chemical ecology [2-7] and the wide range of colony organisations makes the genus an ideal system for exploring social evolution [812]. Two further complex traits found in Lasius are yet to be adequately understood: social parasitism and fungiculture.

Social parasitism implies that one eusocial species depends on the labour force of another [13-15]. The social parasitism exhibited in Lasius is temporary in that it is confined to the early stages of the parasite's colony: the parasitic queen founds her colony through entering a host colony where she kills the resident queen and takes over the worker force $[1,2,13]$. The study of social parasitism has become virtually a little discipline of entomology in itself [2], but the conditions for social parasitism to arise remain poorly understood [13-20]. Social parasitism has evolved many times independently in ants $[2,13,15,21]$, but the evolutionary trajectories at finer systematic scale, e.g., whether it evolved once or multiply within genera, have only recently received detailed attention [15,18,2127]. Fungiculture by ants, termites and beetles, on the other hand, provides a powerful study system for studying the origin and maintenance of mutualism [28]. In ants, fungiculture has evolved independently at least twice: in attines (members of the Myrmicinae), which culture the fungi for food, and in Lasius ants, which use fungi to build composite nest walls [29-33]. The patterns of diversification in the intensely studied attine fungiculture are only gradually starting to be understood, as brought out by recent papers on leaf-cutter fungiculture which reverse earlier impressions of certainty for some important issues $[34,35]$. For inferences on the evolution of the outstanding ecological and social traits including social parasitism and fungiculture in Lasius, a well-founded phylogeny of the genus is needed. There have been three previous studies to resolve the phylogeny of Lasius [36-38], but these have disagreed with each other in significant respects (Fig. 1).

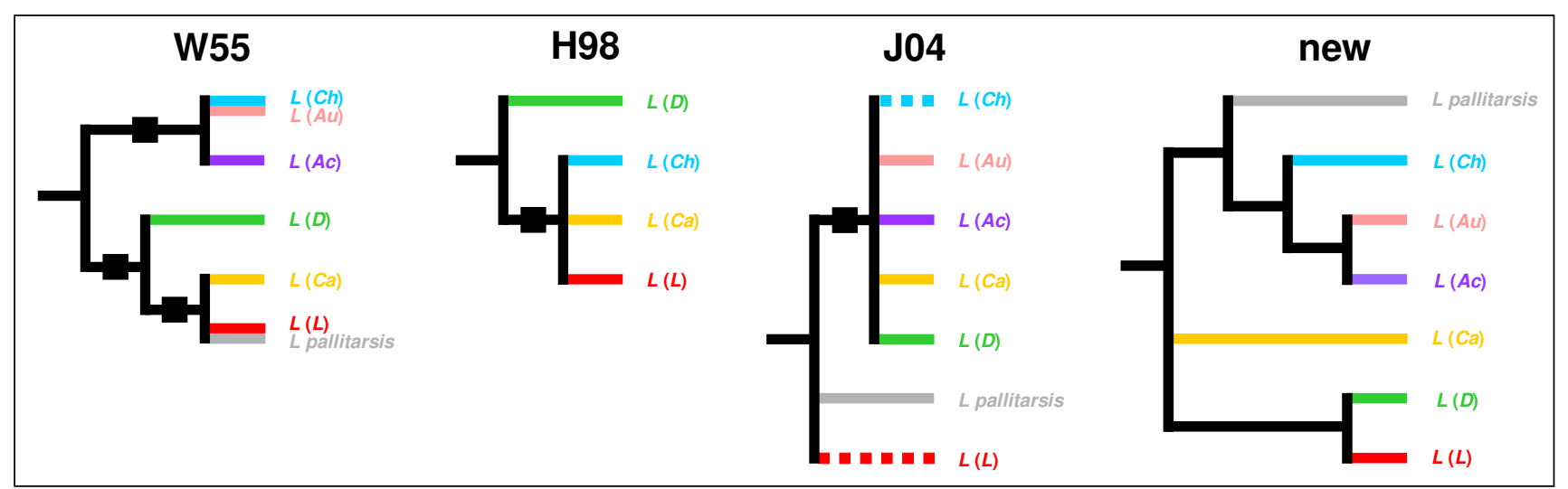

Figure I

Subgenus relationships in the previous and new phylogenetic reconstructions of the genus Lasius. Subgenera abbreviations: Acanthomyops (Ac), Austrolasius ( $A u$ ), Cautolasius (Ca), Chthonolasius (Ch), Dendrolasius (D), Lasius sensu stricto (L). The topologies were extracted from papers by Wilson [36], "W55", Hasegawa [37], "H98", and Janda and coworkers [38], "J04", as well as from the Bayesian tree of combined, concatenated data in Fig. 2 of this paper, "new"; see Methods section for details of the procedure used for inferring the topologies W55, H98, and J04. A dotted line indicates that node support for monophyly of the subgenus was not significant. White squares indicate constraints enforced in constraint analyses using our concatenated data set in order to test the subgenus relationships of W55, H98, and $\mathrm{J} 04$. 
In the present study we attempt to establish a robust phylogenetic framework for the relationships of the Lasius subgenera. We apply Bayesian analysis, a powerful tool in phylogenetic reconstruction of combined data [39] and not previously applied to Lasius. In addition, we also apply Maximum Parsimony analysis (MP); MP represents a completely different computational technique for phylogenetic reconstruction [40] and agreement of the reconstructions by the two independent methods would increase confidence in the tree. Our approach comprised five steps. (i) We combined evidence from different data sets, which for many organisms, including ants, often yields a stronger phylogenetic signal than using the data sets singly $[18,39,41-50]$; specifically, we combined mitochondrial DNA sequence and morphological data. (ii) We explored potential causes of distortion of the molecular phylogenetic signal, namely substitution saturation [51], positive selection $[52,53]$, and compositional heterogeneity [54]. We also assessed which morphological characters may be functionally coupled with social parasitism $[15,54,55]$, because similarities in those characters could reflect convergent adaptations to social parasitic life rather than reflect common ancestry $[56,57]$. We then excluded any suspected cause of distortion in the phylogenetic reconstruction. To address potential issues of character exclusion [58], we explored the effect of excluding those morphological characters suspected to be functionally coupled with social parasitism by repeating the reconstruction when including them. (iii) We explored whether the topologies as inferred from the different data sets are in statistically significant conflict with the phylogenetic framework inferred from the concatenated data which would tend to reduce confidence in the latter $[59,60]$. Our approach was to handle any conflict arising by collapsing the affected node. (iv) We explored whether any of the previous Lasius phylogenies fit our data set as well as our resulting topology. $(v)$ Finally, we used posterior mapping $[61,62]$ to define hypotheses on the evolution of social parasitism and fungiculture in Lasius. In all, the resulting topology provides a solid basis for studying the evolution of the various ecologically and sociobiologically relevant traits of Lasius across subgenera.

\section{Results}

We found no evidence for saturation of substitutions, neither for the $16 S$ ribosomal RNA (16S rRNA) nor for any of the codon positions, single or in combination, of the cytochrome $c$ oxidase subunit I (cox1) data. Tests for positive selection within the cox 1 data indicated that none of the sites was subject to positive selection. But we did detect compositional heterogeneity of sequences for the third codon position of cox 1 . Recoding the nucleotides of these sites to purines and pyrimidines successfully eliminated this effect and we used the recoded sequences for all phylogenetic reconstructions. Scrutinising the morphological data set for characters potentially coupled functionally with social parasitism $[1,2,13,54,55,63,64]$ yielded 37 characters which we hence excluded from our morphological data set. The final data set consisted of 48 samples of 30 species including three outgroup species (Table 1 ) for which a total of 1,265 base pairs (bp), and 64 morphological characters were used for phylogenetic reconstruction (Table 2).

Topology, branch lengths, and Bayesian posterior probabilities of the Markov Chain Monte Carlo (MCMC) analyses of the concatenated data ( $\operatorname{cox} 1$ plus $16 S$ rRNA plus morphology) are given in Fig. 2. Monophyly of all subgenera was strongly supported $(0.98-1.00)$, as were all nodes defining subgenus relationships $(0.99-1.00)$, with exception of one (0.83), connecting Cautolasius to (Dendrolasius + Lasius sensu stricto). Strictly applying a cutoff for node support of $>0.95$, we retrieved two major lineages, $((($ Austrolasius + Acanthomyops $)+$ Chthonolasius $)+$ Lasius pallitarsis) and ((Dendrolasius + Lasius sensu stricto), but the position of Cautolasius relative to these two lineages remains unresolved.

The three individual data set phylogenies ( $\operatorname{cox} 1,16 S \mathrm{rRNA}$, morphology) differed considerably in phylogenetic resolution at subgenus level and above and none of them achieved resolution of all nodes scored by the concatenated data reconstruction. Repeating reconstruction of cox 1 without the third codon position did not yield any well supported nodes that contradicted well supported nodes in the reconstruction using all three codon positions, which confirms the reliability of the result from the applied test for substitution saturation. Comparison of the individual data set topologies with the concatenated data topology at subgenus level and above revealed not a single significant (for MCMC, posterior probability > 0.95) disagreement but rather agreement on well supported nodes. The following nodes of the concatenated topology were supported by the individual data set topologies: cox1 - Cautolasius monophyly, Chthonolasius monophyly, and monophyly of the two Myrmecocystus outgroup species; 165 rRNA - Cautolasius monophyly, (Austrolasius + Acanthomyops), and (Chthonolasius + Lasius pallitarsis + (Austrolasius + Acanthomyops)); morphology - Dendrolasius monophyly and (Austrolasius + Acanthomyops). Including those morphological characters suspected to be functionally coupled with social parasitism, which we therefore had excluded before, resulted in an identical topology, with very similar node support values (Fig. 2), but with a decrease of the value for the node connecting Cautolasius to (Dendrolasius + Lasius sensu stricto) from 0.83 to 0.74 . MP reconstructions based on the concatenated data set significantly (node support threshold of $>70$ for MP) confirmed all significant nodes of the Bayesian reconstructions, including retrieving as significant the node 
Table I: List of samples used for DNA sequencing and morphological analysis

\begin{tabular}{|c|c|c|c|c|c|}
\hline \multirow[t]{2}{*}{ Species } & \multirow[t]{2}{*}{ Subgenus } & \multirow[t]{2}{*}{ Collection locality; collector } & \multicolumn{2}{|c|}{ DDBJ accession numbers } & \multirow[t]{2}{*}{ Museum voucher no } \\
\hline & & & $\operatorname{cox} I$ & I6S rRNA & \\
\hline Lasius arizonicus & Ac. & USA: Arizona, Madera Canyon; C.A. Schmidt & $\mathrm{AB} 370982$ & AB371028 & MMANTI2 \\
\hline L. interjectus & Ac. & USA: Arizona, West Turkey Creek; C.A. Schmidt & $\overline{A B 370981}$ & $\overline{\mathrm{AB} 371027}$ & MMANTI3 \\
\hline L. latipes & Ac. & USA: Wisconsin, Milwaukee; J.M. Raczkowski & $\mathrm{AB} 433922$ & AB433927 & NMANTI 20 \\
\hline L. reginae & $A u$. & Austria: Trandorf; B.C. Schlick-Steiner \& F.M. Steiner & $\overline{\mathrm{AB} 370983}$ & $\overline{\mathrm{AB} 371029}$ & MMANT23 \\
\hline L. flavus & Ca. & Austria: Leiser Berge; B.C. Schlick-Steiner \& F.M. Steiner & $\mathrm{AB} 370984$ & $\mathrm{AB} 371030$ & MMANT22 \\
\hline L. flavus & $\mathrm{Ca}$. & Russia: Ussurisky, Kaimanovka; M. Maruyama & $\mathrm{AB} 370985$ & $A B 371031$ & MMANT38 \\
\hline L. flavus & Ca. & Japan: Gifu-ken, Takayama-shi, M. Maruyama & AB370986 & $\overline{A B 371032}$ & MMANT45 \\
\hline L. nearcticus & $\mathrm{Ca}$. & USA: Arizona, Rustler Park; C.A. Schmidt & AB370987 & $A B 371033$ & MMANTI4 \\
\hline L. mixtus & Ch. & Austria: Göpfritz; B.C. Schlick-Steiner \& F.M. Steiner & $\mathrm{AB} 370988$ & $\mathrm{AB} 371034$ & MMANT30 \\
\hline L. umbratus & Ch. & Japan: Tôkyô-to, Koganei-shi; M. Maruyama & $\overline{\mathrm{AB} 370989}$ & $\overline{\mathrm{AB} 371035}$ & MMANT6 \\
\hline L. capitatus & D. & Japan: Nagano-ken, Matsumoto-shi; T. Komatsu & $\mathrm{AB} 370990$ & $\overline{A B 371036}$ & MMANT44 \\
\hline L. capitatus & D. & Japan: Gifu-ken, Shôkawa-mura; M. Maruyama & $\mathrm{AB} 370993$ & $A B 371039$ & MMANT47 \\
\hline L. capitatus & D. & Japan: Yamanashi-ken, Kitakoma-gun; M. Maruyama & $\overline{\mathrm{AB} 370991}$ & $\overline{\mathrm{AB} 371037}$ & MMANT58 \\
\hline L. capitatus & D. & Japan: Tochigi-ken, Haga-gun; S. Nagashima & $\overline{A B 370992}$ & $\overline{\mathrm{AB} 371038}$ & MMANT62 \\
\hline L. fuji & D. & Japan: Hokkaidô, Maruseppu-chô; Y. Kida & AB370994 & $\underline{A B 371040}$ & MMANTI \\
\hline L. fuji & D. & Russia: Ussurisky, Kaimanovka; M. Maruyama & $\overline{\mathrm{AB} 370995}$ & $\overline{A B 371041}$ & MMANT34 \\
\hline L. fuliginosus & D. & Austria: Urschendorf; B.C. Schlick-Steiner \& F.M. Steiner & $\mathrm{AB} 370996$ & $A B 371042$ & MMANT24 \\
\hline L. fuliginosus & D. & Austria: Vienna; B.C. Schlick-Steiner \& F.M. Steiner & $\overline{A B 370997}$ & $\overline{A B 371043}$ & MMANT70 \\
\hline L. nipponensis & D. & Russia: Ussursky, Vityas; M. Maruyama & $\mathrm{AB} 371001$ & AB371047 & MMANT33 \\
\hline L. nipponensis & D. & Japan: Hokkaidô, Sapporo-shi; M. Maruyama & $\mathrm{AB} 370998$ & $\mathrm{AB} 371044$ & MMANT63 \\
\hline L. nipponensis & D. & Japan: Nagano-ken, Fujimi-chô; M. Maruyama & $\overline{\mathrm{AB} 370999}$ & $\overline{\mathrm{AB} 371045}$ & MMANT64 \\
\hline L. nipponensis & D. & China: Hubei, Xianfeng; T. Kishimoto & $\mathrm{AB} 371000$ & $\overline{A B 371046}$ & MMANT67 \\
\hline L. orientalis & D. & Japan: Hokkaidô, Shari-chô; Y. Kida & $\mathrm{AB} 371002$ & $\overline{\mathrm{AB} 371048}$ & MMANT4 \\
\hline L. orientalis & D. & Japan: Gifu-ken, Kamitakara-mura; M. Maruyama & $\overline{\mathrm{AB} 371003}$ & $\overline{\mathrm{AB} 371049}$ & MMANT60 \\
\hline L. spathepus & D. & Japan: Shimane-ken, Oki-shotô; T. Shimada & $\mathrm{AB} 371006$ & $\mathrm{AB} 371052$ & MMANT32 \\
\hline L. spathepus & D. & Japan: Yamanashi-ken, Nagasaka-chô; M. Maruyama & $\mathrm{AB} 371005$ & $\overline{A B 371051}$ & MMANT74 \\
\hline L. spathepus & D. & Japan: Kyôto-fu, Kyôto-shi; N. Fujiwara & $\mathrm{AB} 371007$ & AB371053 & MMANT77 \\
\hline L. alienus & $L$. & Austria: Braunsberg; B.C. Schlick-Steiner \& F.M.Steiner & $\mathrm{AB} 371008$ & $\mathrm{AB} 371054$ & MMANT2I \\
\hline L. austriacus & L. & Austria: Feldberg; B.C. Schlick-Steiner \& F.M. Steiner & $\overline{\mathrm{AB} 371009}$ & $\overline{\mathrm{AB} 371055}$ & MMANT27 \\
\hline L. brunneus & $L$. & Austria: Rassing; B.C. Schlick-Steiner \& F.M. Steiner & $\overline{\mathrm{AB} 371010}$ & $\overline{\mathrm{AB} 371056}$ & MMANT25 \\
\hline L. emarginatus & L. & Austria: Vienna; B.C. Schlick-Steiner \& F.M. Steiner & $\mathrm{AB} 371011$ & $\mathrm{AB} 371057$ & MMANT4I \\
\hline L. hayashi & L. & Japan: Gifu-ken, Kamitakara-mura; M. Maruyama & $\overline{\mathrm{AB} 371013}$ & $\overline{\mathrm{AB} 371059}$ & MMANT46 \\
\hline L. hayashi & L. & Japan: Chiba-ken, Kimitsu-shi; M. Maruyama & $\mathrm{AB} 371012$ & $\mathrm{AB} 371058$ & MMANT54 \\
\hline L. japonicus & L. & Japan: Kagawa-ken, Takamatsu-shi; F. Ito \& Y. Ikeshita & $\mathrm{AB} 371015$ & $A B 371061$ & MMANTI9 \\
\hline L. japonicus & $L$. & Russia: Ussurisky, Kaimanovka; M. Maruyama & $\overline{\mathrm{AB} 371017}$ & $\overline{\mathrm{AB} 371063}$ & MMANT37 \\
\hline L. japonicus & L. & Japan: Chiba-ken, Kimitsu-shi; M. Maruyama & $\mathrm{AB} 371014$ & $A B 371060$ & MMANT55 \\
\hline L. japonicus & L. & Japan: Hokkaidô, Sapporo-shi; T. Toida & $\overline{A B 371016}$ & $\overline{\mathrm{AB} 371062}$ & MMANT76 \\
\hline L. neglectus & L. & Hungary: Budapest; B.C. Schlick-Steiner \& F.M. Steiner & $\overline{\mathrm{AB} 371018}$ & $\overline{\mathrm{AB} 371064}$ & MMANT20 \\
\hline L. niger & L. & Austria: Vienna; B.C. Schlick-Steiner \& F.M. Steiner & $\mathrm{AB} 371019$ & $\mathrm{AB} 371065$ & MMANT26 \\
\hline L. platythorax & L. & Austria: Moosbrunn; B.C. Schlick-Steiner \& F.M. Steiner & $\mathrm{AB} 371020$ & $\overline{A B 371066}$ & MMANT28 \\
\hline L. productus & L. & Japan: Kagawa-ken, Takamatsu-shi; F. Ito \& Y. Ikeshita & $\mathrm{AB} 371021$ & AB371067 & MMANTI8 \\
\hline L. sakagamii & L. & Japan: Gifu-ken, Gifu-shi; J. Heinze & $\mathrm{AB} 371022$ & $\mathrm{AB} 371068$ & MMANT29 \\
\hline L. sakagamii & L. & Japan: Tôkyô-to, Edogawa-ku; M. Maruyama & $\overline{A B 371023}$ & $\overline{A B 371069}$ & MMANT56 \\
\hline L. sp. $3^{\circ}$ & L. & Russia: Ussurisky, Kaimanovka; M. Maruyama & $\overline{\mathrm{AB} 371024}$ & $\overline{\mathrm{AB} 371070}$ & MMANT40 \\
\hline L. pallitarsis & $L$ pallitarsis & USA: Arizona, Apache Ntl Forest; C.A. Schmidt & $\mathrm{AB} 371025$ & $A B 371071$ & MMANTI5 \\
\hline Myrmecocystus mimicus & n.a. & USA: California, Carrizo Plain; P.S. Ward & $\mathrm{AB} 433923$ & $\overline{\mathrm{AB} 433928}$ & MMANTII7 \\
\hline Myrmecocystus mendux & n.a. & USA: Arizona, Pima Canyon; C.A. Schmidt & $\mathrm{AB} 433920$ & AB433925 & MMANT66 \\
\hline Formica japonica & n.a. & Japan: Tôkyô-to, Shinjuku-ku; M. Maruyama & $\mathrm{AB} 371026$ & $\overline{A B 371072}$ & MMANT7 \\
\hline
\end{tabular}

Voucher specimens have been deposited at the National Science Museum, Tokyo, with the numbers indicated and a reference to this publication (Maruyama et al. 2008/voucher no). Abbreviations of Lasius subgenera are Acanthomyops (Ac), Austrolasius (Au), Cautolasius (Ca), Chthonolasius (Ch), Dendrolasius (D), Lasius sensu stricto ( $L$ ). Subgenus was not applicable (n.a.) for the outgroup taxa, Myrmecocystus mimicus and M. mendux, and Formica japonica.

connecting Cautolasius to (Dendrolasius + Lasius sensu stricto). This pattern persisted in the MP analysis when using the concatenated data including those morphologi- cal characters suspected to be functionally coupled with social parasitism, with one exception: the node connecting Dendrolasius to Lasius sensu stricto was then no longer 
Table 2: Character counts and substitution models for partitions

\begin{tabular}{|c|c|c|c|c|c|c|}
\hline & Characters total & $\begin{array}{l}\text { Characters variable } \\
\text { but parsimony } \\
\text { uninformative }\end{array}$ & $\begin{array}{l}\text { Characters } \\
\text { parsimony } \\
\text { informative }\end{array}$ & $\begin{array}{l}\text { AIC model } \\
\text { selection }\end{array}$ & $\begin{array}{l}\text { hLRT model } \\
\text { selection }\end{array}$ & $\begin{array}{l}\text { Model used in final } \\
\text { MCMC runs }\end{array}$ \\
\hline cox I position I & 281 & 17 & 22 & $\mathrm{GTR}+1+\Gamma$ & $\mathrm{GTR}+\Gamma$ & GTR $+1+\Gamma$ \\
\hline coxl position 2 & 281 & 8 & 2 & F8I & F8I & F8I \\
\hline coxI position3 RY & 281 & 28 & 87 & - & - & F8I \\
\hline I6s rRNA & 422 & 45 & 83 & $\mathrm{GTR}+1+\Gamma$ & $\mathrm{GTR}+\Gamma$ & $\mathrm{GTR}+\mathrm{I}+\Gamma$ \\
\hline morphology & 64 & 10 & 54 & - & - & $M k+\Gamma$ \\
\hline
\end{tabular}

RY purine + pyrimidine coding, otherwise the original nucleotide sequence was used. "-" under model selection indicates that AIC and hLRT model selection were not applicable for the partition.

supported (Fig. 2). Considering the lack of significant disagreement between the signals in the individual data set phylogenies and the confirmation of the Bayesian topology by Maximum Parsimony reconstructions, we regard the Bayesian concatenated data topology as a phylogenetic framework sufficiently robust for use in subsequent evolutionary hypotheses ("new" topology in Fig. 1).

Subsequently, we also made a Bayesian reconstruction of the concatenated molecular data sets ( $\operatorname{cox} 1$ plus $16 S$ $r R N A$ ), without any morphological data, to allow for DNA based estimates of branch length. This tree (inset in Fig. 2) was in large agreement with the other Bayesian trees, in topology and branch lengths, but in addition to the node connecting Cautolasius to (Dendrolasius + Lasius sensu stricto), three previously well supported nodes now lacked significant support (Acanthomyops monophyly; node connecting Chthonolasius to (Austrolasius + Acanthomyops); Lasius sensu stricto monophyly).

In additional rounds of reconstruction, we enforced the subgenus relationships recovered in three previous phylogenetic analyses [36-38] as constraints (Fig. 1) on our concatenated data. All reconstructions with constraints had lower likelihood values than the reconstruction without constraint (Table 3 ) and, on the basis of our concatenated data, Bayes factor analysis revealed very strong evidence against all previously suggested subgenus relationships (Table 4).

The Bayesian posterior probabilities for the occurrence of social parasitism and fungiculture at the nodes of the phylogenetic framework above subgenus level ("new" topology in Fig. 1) are shown in Table 5. For eight of the ten possible inferences a state was significantly inferred ( $p>$ $0.95)$, for the remaining two the probability values were 0.70 and 0.82 .

\section{Discussion and Conclusion The new phylogenetic framework}

The new phylogenetic framework we present clarifies the relationships of all but one subgenus, namely the position of Cautolasius relative to the other subgenera: MP reconstructions significantly support the topology, Cautolasius + (Dendrolasius + Lasius sensu stricto), and Bayesian reconstructions do not contradict it. Given the lack of significant support in the Bayesian tree, we nevertheless subsequently refrain from considering the node as resolved ("new" topology in Fig. 1). This lack of significant resolution does not affect considerations on the evolution of social parasitism and fungiculture, though, because the ancestral state of Lasius was absence of both traits (Table 5), and because also Cautolasius displays neither trait. A significantly supported sister-status to (Dendrolasius + Lasius sensu stricto) thus would not alter any conclusions (see discussion below). The previous phylogenies were recovered by various methods and we discuss below how the methods applied may have influenced the respective results. Taken together, the reasons for the increased robustness that we postulate for the new phylogenetic framework, which robustness is highlighted also by the confirmation of our Bayesian topology by our MP reconstructions, may be that (1) we excluded potential causes of phylogenetic distortion and (2) used additional analysis methods, that (3) the phylogenetic signal of combined data is potentially stronger than that of individual data sets $[18,39,41-50]$, especially when applying Bayesian inference [39], that (4) all nodes but one at subgenus level or above were significantly supported in our concatenated analysis (Fig. 2), and that (5) we did not recover any disagreement between the individual data set phylogenies and the concatenated data topologies. Nevertheless, because the molecular data of this paper all derive from mitochondrial DNA, we cannot absolutely exclude that the tree is influenced by introgression at very shallow levels. Nuclear pseudogenes are also a concern, but we consider it unlikely that we amplified these because neither reading frame shifts nor sequence ambiguities were apparent. The possibilities of incomplete lineage sorting and of selection driven by symbionts which are in disequilibrium with mtDNA [65] cannot be ruled out, but such effects are unlikely to confound clade history at a deeper level, such as that of subgenera. It remains true that future 


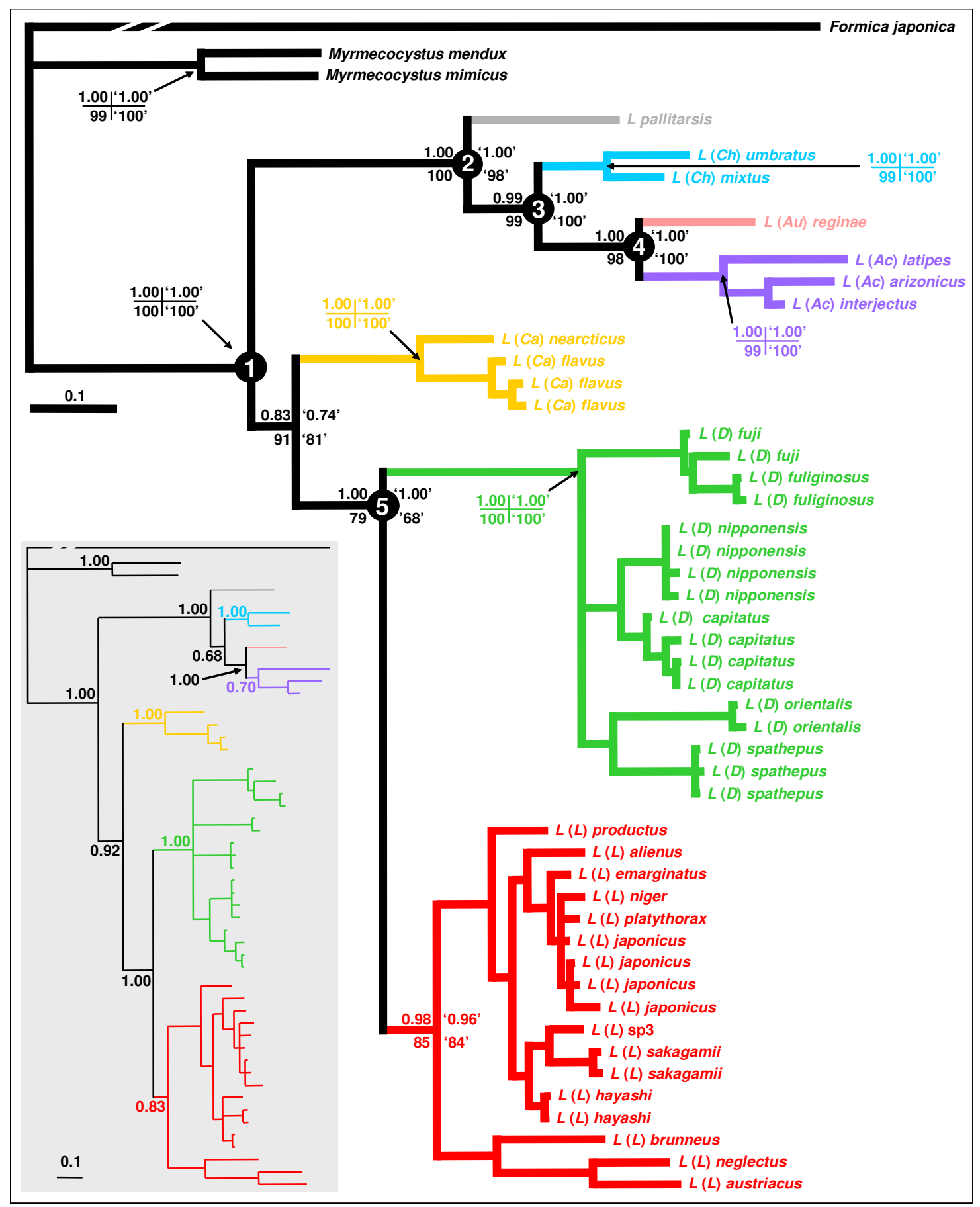

\section{Figure 2}

Bayesian topology from the analysis of the combined, concatenated data. Subgenera are abbreviated as in Fig. I. The tree is a consensus tree resulting from a Bayesian analysis of our concatenated data set based on cox I plus I6S rRNA plus morphology. The credibility values are posterior probabilities derived from 20,000 trees representing 2 million generations after burnin (upper left), bootstrap values from the $50 \%$ majority-rule consensus MP tree of the same data (lower right, in quotation marks); values for nodes following the basal divergence within subgenera are omitted. The node numbers refer to the inferred ancestral character states given in Table 5. The inset tree on grey background is a Bayesian tree based on cox I plus I6S rRNA and the credibility values are posterior probabilities derived from 20,000 trees representing 2 million generations after burnin. 
Table 3: Summary of results from Bayesian analyses

\begin{tabular}{|c|c|c|c|c|c|c|}
\hline Data & ngens & $\ln (\mathrm{Ar})$ & $\ln (\mathrm{Hr})$ & asdsf & burnin & $99 \%$ \\
\hline concatenated data: coxl_position $3 \mathrm{RY}+16 \mathrm{~S} r R N A+$ morphology $(\mathrm{Mk}+\Gamma)$ & 10.0 & -5474.9 & -5533.3 & 0.002 & 9.0 & 13369 \\
\hline W55 constraint on concatenated data & 10.0 & -5593.4 & -5671.6 & 0.002 & 9.0 & 11893 \\
\hline H98 constraint on concatenated data & 10.0 & -5623.8 & $-57 \mid 7.0$ & 0.063 & 9.0 & 15960 \\
\hline J04 constraint on concatenated data & 10.0 & -5576.0 & -5630.7 & 0.002 & 9.0 & 13706 \\
\hline
\end{tabular}

ngens (number of generations) and burnin are given in units of a million; Ar and Hr refer to the arithmetic and harmonic means, averaged over the simultaneous runs; asdsf = average standard deviation of split frequencies; $99 \%$ refers to the number of trees sampled from the $99 \%$ credible set.

studies using multiple nuclear genes are desirable to confirm our findings.

The new phylogenetic framework presented here confirms the monophyly of the six subgenera. The new framework also affirms the taxonomic placement of Acanthomyops as a subgenus of Lasius [66]. Moreover, there is additional evidence for treating Lasius pallitarsis as a separate, monotypic subgenus, as suggested earlier [38]. Detailed morphological characterisation of the new subgenus and taxonomic implications will be followed up elsewhere in the frame of a formal taxonomic revision.

The evolution of the Lasius subgenera occurred in two major lineages, the first lineage comprising Acanthomyops, Austrolasius, Chthonolasius, and Lasius pallitarsis, and the second lineage comprising Dendrolasius, and Lasius sensu stricto, with Cautolasius probably belonging to the second lineage (Fig. 2). Within the first lineage Acanthomyops and Austrolasius form a crown-group which is sister to Chthonolasius.

\section{Comparison with previous phylogenies}

The new framework disagrees with previous topologies [36-38]. Given that we actively sought to exclude potential factors causing phylogenetic distortion from our data, and that the previous phylogenies disagreed with each other (Fig. 1), we suggest that where our topology disagrees with previous ones the new one is preferable (Table 4). Examination of the reasons for disagreements between the new topology and previous schemes is desirable and we now address this.

The phylogeny by Wilson published in 1955 [36] (W55) is the only one of the previous phylogenies that hypothesised the existence of two major lineages as recovered in the new framework. In terms of subgenera, the two W55 lineages agree with those of the new framework with the exception of Lasius pallitarsis (treated as L. sitkaensis and believed to belong to Lasius sensu stricto at the time [36]). However, there are disagreements within the two lineages. Within the first lineage, the situation is ambiguous because Austrolasius, found in the new framework to be sister to Acanthomyops, was treated as part of Chthonolasius. Within the second lineage, the relations differ in that Lasius sensu stricto is considered sister to Cautolasius in W55, whereas it is sister to Dendrolasius in the new framework. Reasons for the disagreements could include that W55 is based on morphological information only, and that it lacked a formal reconstruction algorithm.

In the phylogeny by Hasegawa of 1998 [37] (H98), there was only one significantly supported (i.e., for MP, node support > 70 [67]) subgenus relationship, i.e., that Cautolasius, Chthonolasius, and Lasius sensu stricto form a crowngroup sister to Dendrolasius, and this is not supported by the new framework. Reasons for the disagreement could include that $\mathrm{H} 98$ had very limited taxon sampling, and that no check for compositional heterogeneity was undertaken: The reconstruction methods applied (Neighbour Joining and Maximum Parsimony) could also contribute as the genetic distance based Neighbour Joining reconstruction is known to have the limitation that rate variation among sites cannot be accurately accounted for [68], and as MP ignores the possible existence of a range of alternative topologies that are not significantly less likely than the most parsimonious one, even though they would require more evolutionary changes [40].

The subgenus relationships recovered by Janda and coworkers in 2004 [38] (J04), placing Lasius sensu stricto in a sister clade to the rest, and within this clade Lasius pallitar-

Table 4: Comparing previous Lasius phylogenies with the new phylogenetic framework

\begin{tabular}{lll}
\hline Data & Bayes factor & Interpretation \\
\hline concatenated vs. W55 constraint on concatenated & 276.7 & very strong evidence against W55 constraint \\
concatenated vs. H98 constraint on concatenated & 367.4 & very strong evidence against H98 constraint \\
concatenated vs. J04 constraint on concatenated & 194.9 & very strong evidence against J04 constraint \\
\hline
\end{tabular}

Summary of Bayes factor comparisons and interpretation after [96]. 
Table 5: Bayesian posterior probabilities for the occurrence of social parasitism and fungiculture as ancestral character states

\begin{tabular}{ccccccc}
\hline Node & \multicolumn{2}{c}{ Social parasitism } & & \multicolumn{2}{c}{ Fungiculture } \\
\cline { 2 - 3 } \cline { 5 - 6 } & no & yes & & no & yes \\
\hline I & $\mathbf{0 . 9 8}$ & 0.02 & & $\mathbf{1 . 0 0}$ & 0.00 \\
2 & 0.70 & 0.30 & & $\mathbf{0 . 9 8}$ & 0.02 \\
3 & 0.00 & $\mathbf{1 . 0 0}$ & & 0.82 & 0.18 \\
4 & 0.00 & $\mathbf{1 . 0 0}$ & & $\mathbf{1 . 0 0}$ & 0.00 \\
5 & $\mathbf{0 . 9 7}$ & 0.03 & & $\mathbf{0 . 9 8}$ & 0.02 \\
\hline
\end{tabular}

"no" indicates absence, "yes" indicates presence; the posterior probabilities were estimated using SIMMAP and the last 2000 postburnin trees of the 20,000 used to derive the consensus tree of Fig. 2 . Significantly positive values $(p>0.95)$ are given in bold. Node numbers refer to those shown in Fig. 2.

sis sister to the rest, are not supported by the new framework. However, our data confirm two important aspects of J04, the allocation of Acanthomyops to the genus Lasius, and the discovery that Lasius pallitarsis does not belong to Lasius sensu stricto or any other of the established subgenera. Reasons for the disagreements with the new framework could include that the DNA data of J04 add up to a total of only $568 \mathrm{bp}$ and that no check for compositional heterogeneity was undertaken. Moreover, while the combination of molecular with other data by Janda et al. marks an advance in the history of Lasius phylogeny, the morphological data included 33 characters (Additional File 1) that, as indicated by other studies $[1,2,12,51,52,60,61]$, may possibly be coupled functionally with social parasitism. Scrutiny in morphological character selection was recently confirmed as crucial in phylogenetic reconstruction [69]. Also, the occurrence of social parasitism itself was included as character. These characters might contribute to grouping all parasitic subgenera together in an unresolved crown group as indeed is the case in $\mathrm{J04}$ (additionally including Cautolasius), whereas they were distributed over the two major lineages in the new framework. The phylogenetic reconstruction methods applied (Maximum Parsimony) could possibly have contributed to suboptimal reconstruction as compared to Bayesian inference, especially for combined data sets, demonstrated after the publication of Janda et al. [39]. Possibly none of these various causes had a strong effect per se, as suggested by rather minor differences between the Bayesian trees based on the concatenated data excluding versus including those morphological characters suspected to be coupled with social parasitism as well as between the Bayesian and the MP trees when excluding those morphological characters (Fig. 2). The various causes may, however, have added up to a significant effect, as is suggested by the lack of significant support for the sister-group relationship in the MP tree when including those morphological characters (0.68), which node scored a value of 1.0 in the Bayesian tree independently of excluding or including the characters.

\section{Hypotheses on the evolution of social parasitism and fungiculture}

The new phylogenetic framework ("new" topology in Fig. 1 ) and the reconstructed ancestral states (Table 5) suggest that both social parasitism and fungiculture evolved two times independently within Lasius, once in each of the major lineages (Fig. 3). For social parasitism such parallel evolution within a monophyletic group is not surprising in general. It has long been established that the combination of certain traits resulted in a predisposition for social parasitism in two (Myrmicinae and Formicinae) of the 21 [70] ant subfamilies $[2,15,71]$. Evidence that social parasitism also evolved multiple times within tribes $[16,24,72]$ or within genera $[15,21,22,25,27]$ confirms the principle for lower taxonomic levels. Having a reliable phylogenetic framework for Lasius facilitates examination of temporary social parasitism, considered less derived than other types of social parasitism $[13,15,24]$. One factor that may have favoured the rise of parasitism in Lasius may derive from their colony organisation: In several species of the non-parasitic subgenera, Lasius sensu stricto and Cautolasius, the lack of aggression between different single-queened colonies has been reported $[8,17,73,74]$. Whereas this behaviour concerns intraspecific interactions, the predisposition to reduce aggression may have been important for social parasitism to arise. The paramount significance of reduced aggression is illustrated by the chemical disguise of founding queens of Chthonolasius to appease host workers $[1,2]$ and the exceptional winter activity of L. (Ch.) mixtus to ease entry to the then less aggressive host colonies [1]. Characterisation of such potentially preadaptive traits and search for them in extant non-parasitic Lasius species might help in finding potential early stages of incipient social parasitism. Such discoveries would then contribute to resolving mechanisms in the evolution of social parasitism in general [1417]. Fungiculture on the other hand only is known from one other group of ants, the Attini (Myrmicinae). It is established that fungiculture arose only once in attines $[35,75]$ and the Lasius situation might thus indicate a stronger predisposition to evolve fungiculture for ants generally.

For the evolution of both fungiculture and social parasites two pairs of alternative hypotheses remain (Fig. 3), both concerning the lineage of ( ( Lasius pallitarsis + ((Chthonolasius $+($ Austrolasius + Acanthomyops $)))$. This is because for both traits the probability value for the ancestral state for one node was below 0.95 (Table 5). For each trait there is one scenario considering an earlier origin with subsequent loss in the respective lineage, and the other considering an origin at a later stage in the respective lineage. 


\section{Social parasitism}

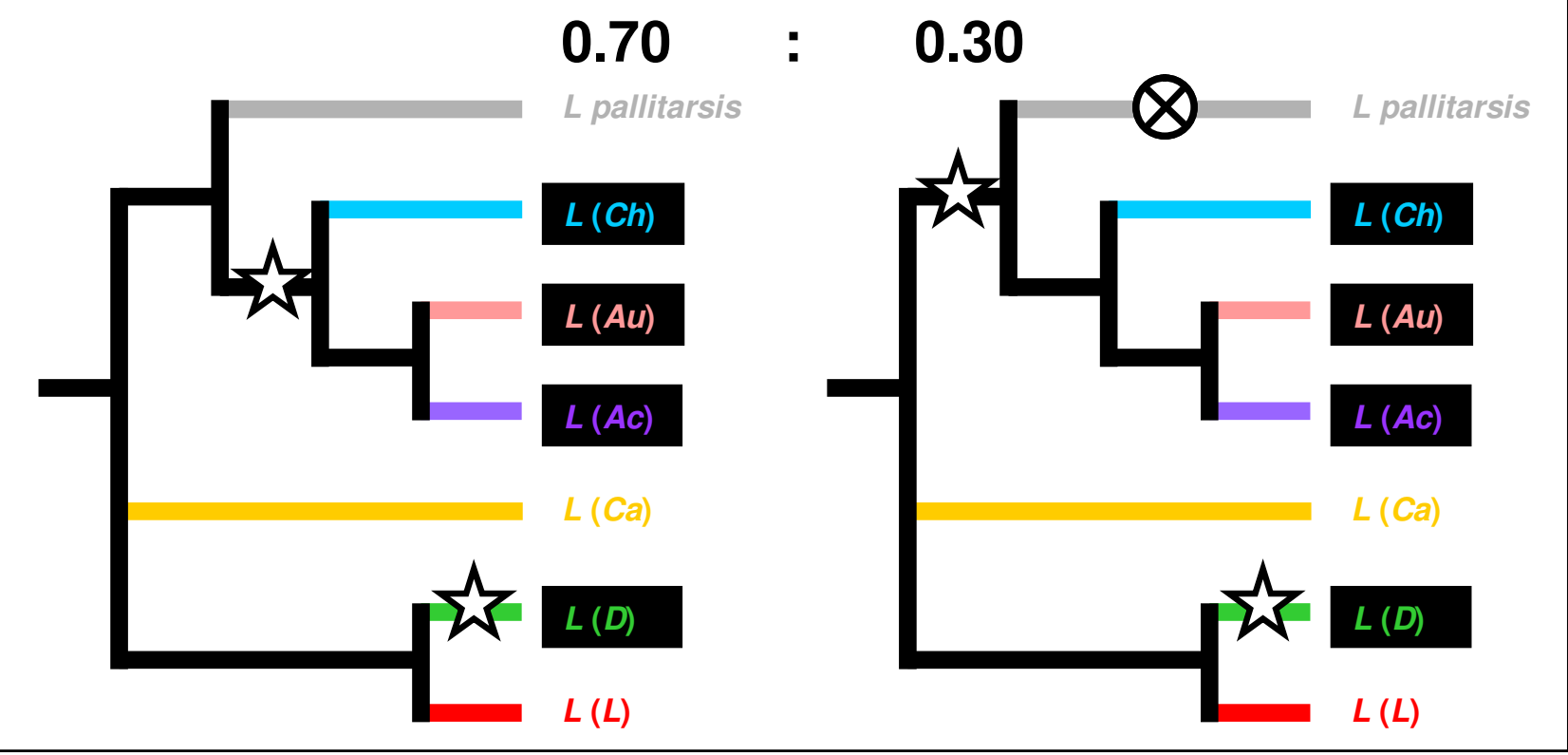

\section{Fungiculture}

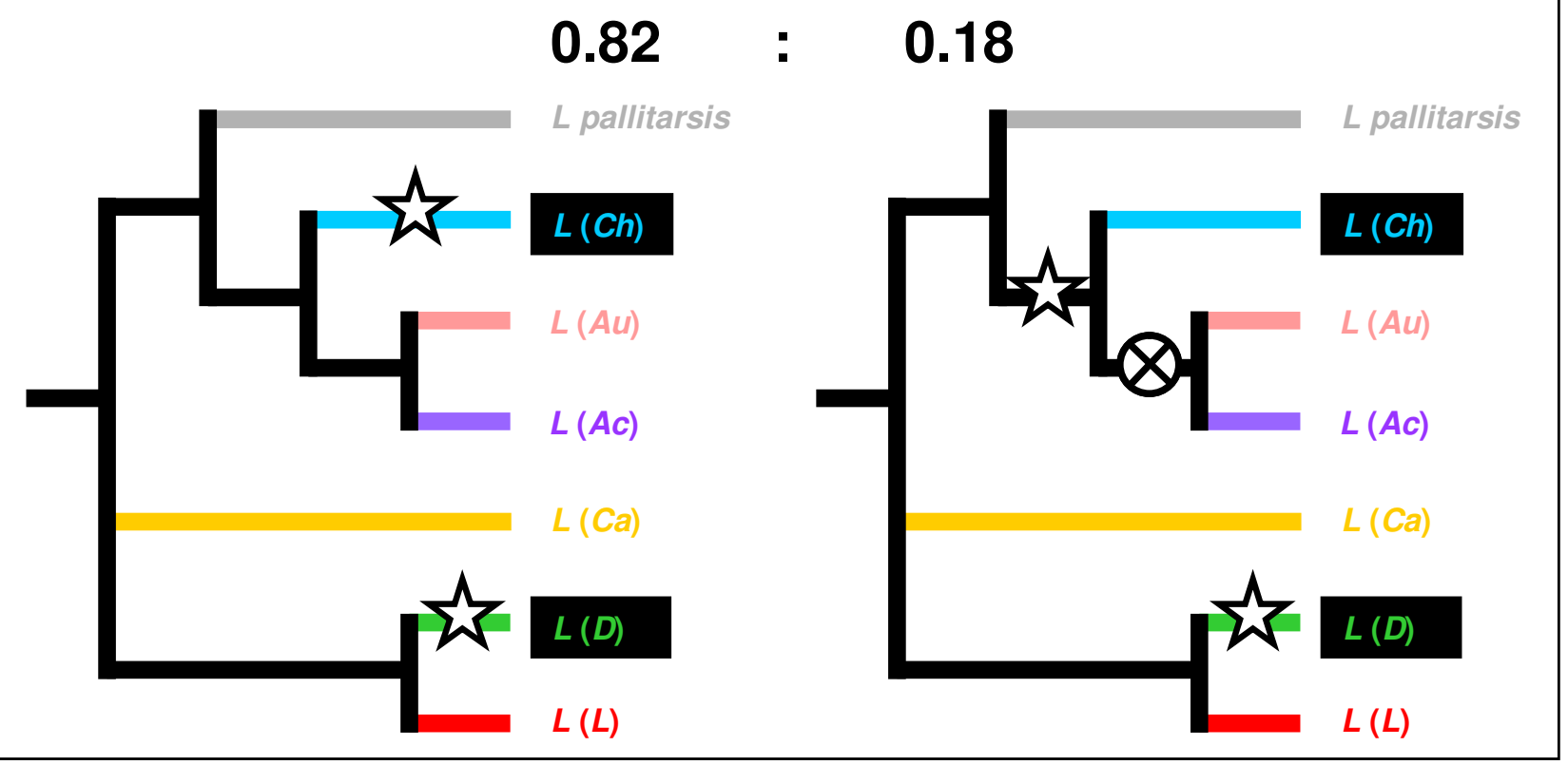

Figure 3

Hypotheses on the evolution of social parasitism and fungiculture in Lasius ants. Subgenera are abbreviated as in Fig. I. Asterisks indicate the emergence of the trait, crossed circles its loss. Subgenera currently displaying social parasitism or fungiculture are indicated by frames filled black. Alternative hypotheses are offered for the evolution of social parasitism and fungiculture due to two insignificant results of the ancestral character state reconstruction in Table 5, with probabilites for the competing scenarios given, based on the values in Table 5. 
Concerning both traits the hypothesis of a reversal is less likely from the point of view of biological realism because it is less parsimonious, and also because the probability values for the respective nodes ( 2 and 3 ) indicate, though not significantly, that social parasitism and fungiculture had not yet evolved at those stages $(0.70$ and 0.82$)$. Still, we cannot formally refute the reversal scenarios here, given the lack of statistical support, and briefly discuss them in the below.

For social parasitism, a reversal has been considered generally unlikely $[2,17]$. On the other hand, reversal from temporary social parasitism may be more likely than reversal from any other, more derived type of social parasitism. For example, temporarily socially parasitic ant species of Formica sensu stricto that are capable of alternative nest foundation through colony budding or adoption into another colony show a certain flexibility in the nest foundation mode in this type of social parasitism [1]. On the other hand, the fact that Acanthomyops, Austrolasius, and Chthonolasius form an entirely socially parasitic clade shows that temporary social parasitism may in fact be a stable trait and makes reversal appear less likely.

Once arisen, fungiculture is not known to have been lost in insects and loss has been regarded as improbable [28], which provides an additional argument against the scenario involving a loss in Lasius. It may, however, be more probable in the Lasius case: fungiculture for nest building is probably less likely to entail a high dependence of the ants as compared to fungiculture for nutrition, which involves physiological adaptations [75].

It is not possible to definitely decide in favour of any of the alternative hypotheses at present, neither concerning social parasitism nor fungiculture, but it is worth considering the question further because a plausible loss of either would be of considerable evolutionary significance. For both traits the fossil record may offer answers in combination with a sound molecular clock for Lasius, for social parasitism by revealing the queen morphology of the ancestor of the entire major lineage, for fungiculture by a preserved fungal nest structure. Laboratory experiments may also be helpful for the analysis of both traits, for social parasitism by checking whether any of the temporary social parasites of the lineage are capable of independent colony foundation, and for fungiculture whether Chthonolasius colonies can be maintained when deprived of their fungus.

This study provides a basis for studying the evolution of the various ecologically and sociobiologically relevant traits across the ca. 100 [70] species of Lasius, by establishing a phylogenetic framework and resolving the position of six of the seven lineages at subgenus level. We have used the framework to define hypotheses of the evolution of two outstanding traits, social parasitism and fungiculture, the evolution of which continues to pose riddles to evolutionary biology. Our results suggest that both traits arose twice in Lasius which opens up new opportunities for comparative analyses in a close phylogenetic relationship. We present competitive hypotheses that either do or do not involve reversal from the traits.

\section{Methods \\ The study system}

The species of the ant genus Lasius are currently placed in six subgenera, Acanthomyops, Austrolasius, Cautolasius, Chthonolasius, Dendrolasius, and Lasius sensu stricto [70]. The most recent taxonomic revision at the genus level dates back to 1955 [36]. It recognised four subgenera: Cautolasius, Chthonolasius, Dendrolasius, and Lasius sensu stricto. The fifth subgenus, Austrolasius, was established in 1967 [70] and includes one species which had up to then been placed in Chthonolasius. The sixth subgenus, Acanthomyops, has an unstable history in that its status changed several times between that of a separate genus and being a subgenus, mostly of Lasius [70]. Evidence for its inclusion into Lasius has accumulated $[38,76]$ and it was therefore formally returned to Lasius [66]. Monophyly of the subgenera is supported by various pieces of evidence [77], except for Lasius sensu stricto. Lasius sensu stricto harbours one taxon, L. pallitarsis, which on morphological and molecular grounds has been hypothesised to best constitute a separate subgenus [38]. We here validate these earlier findings [38].

Social parasitism is confined to four subgenera, Acanthomyops, Austrolasius, Chthonolasius, and Dendrolasius, with all species of these subgenera obligatorily displaying this lifestyle $[1,66]$. One subgenus, Dendrolasius, is hyperparasitic in that it parasitises parasitic Chthonolasius species $[1,36]$. Fungiculture is known from two subgenera, Chthonolasius, and Dendrolasius [34] and, as far as known, all members of the two subgenera use fungi (B.C. SchlickSteiner, unpublished data; M. Maruyama, unpublished data; [1]), although New World species still await study.

\section{Taxon sampling}

The material of this study is listed in Table 1. It comprises 27 species of Lasius (including one undescribed) representing all 6 of the subgenera currently recognised as well as Lasius pallitarsis. We thus present data on more than a quarter of the currently 100 valid extant Lasius species [70], covering both the Palaearctic and the Nearctic regions. The number of species per subgenus ranged from one to 11 . Only two and three species each of Chthonolasius and Acanthomyops, respectively, were analysed, with each sample carefully chosen to be unambiguously identified to species (because the species of these subgenera 
are known for their habitual multidirectional hybridisation $[78,79]$ which is likely to compromise the resolving power of gene sequences [80] and distorts morphological characters [79]). To account for intraspecific diversity, up to four colonies per species were included wherever possible. Two species of Myrmecocystus, which genus is sister to Lasius $[[42,49]$; confirmed by a personal communication by P.S. Ward, of February 2008], as well as Formica japonica were used as outgroup. Species were identified according to $[1,36,77,81-83]$. Voucher specimens are deposited at the National Science Museum, Tokyo under the voucher numbers listed in Table 1.

\section{Molecular protocols}

Some samples were irreplaceable dried museum specimens. Therefore, genomic DNA was extracted from whole body using a DNAeasy tissue kit (Qiagen, Hilden, Germany) using established protocols [84] without any damage to the voucher specimens. We used $1 \mu$ of DNA (25 $50 \mathrm{ng} / \mu \mathrm{l})$ as template for PCR amplification. A $490-550$ bp region of $16 S$ rRNA was amplified and sequenced using primers "16Sar-L" 5'-CGCCTGTTTATCAAAAACAT3' and "16Sar-L2" 5'-CCGGTCTGAACTCAGATCATG-3' originally taken from [85] but the latter one slightly altered and thus renamed. A ca. 900 bp region of cox1 was amplified and sequenced using the new, degenerated primers "Lasius-L" 5'-TAYCCGCCATTAGCTTCAAA-3' and "Lasius-R" 5'-TGAAATTAAGGATCCAATWGA-3'. Reactions were carried out at $10 \mu \mathrm{l}$ volumes in a PCR Thermal Cycler MP (TaKaRa Bio Inc.) under the following conditions: a first cycle of $94^{\circ} \mathrm{C}$ for $3 \mathrm{~min}$, followed by 35 cycles of $94^{\circ} \mathrm{C}$ for $30 \mathrm{~s}$, annealing at $50^{\circ} \mathrm{C}$ for $50 \mathrm{~s}$, and finally $72^{\circ} \mathrm{C}$ for $1 \mathrm{~min}$ for the $16 \mathrm{~S} r R N A$; for $\operatorname{cox} 1$ all settings were identical except for annealing which was set to $42^{\circ} \mathrm{C}$ for 1 min $15 \mathrm{~s}$. PCR products were purified with $0.5 \mu \mathrm{l}$ of ExoSap-IT (GE Healthcare Life Sciences). All products were sequenced in both directions using BigDye Terminator v3.1 (Applied Biosystems) on an ABI 3100 Avant DNA Sequencer (Applied Biosystems) at the National Science Museum, Tokyo. The sequence data were deposited at DNA Data Base of Japan, DDBJ (see Table 1 for accession numbers).

\section{Exploration of molecular data concerning potential causes for phylogenetic distortion}

The 16S rRNA and cox1 sequences were aligned with default settings of the program Clustal X v1.83 [86]; ambiguously aligned sites in the $16 S$ rRNA alignment were excluded. We partitioned the $\operatorname{cox} 1$ sequences into the first, second and third codon positions using the program DAMBE v4.2.13 [87]. This program was also used to perform tests for the saturation of substitutions [88] on the $\operatorname{cox} 1$ and $16 S$ rRNA data. For $\operatorname{cox} 1$ all codon positions were tested simultaneously, as well as separately. We found no indication of substitution saturation (see Results for detail), but we additionally performed the cox1 MCMC analysis without the third codon position.

To detect potential positive selection we used the program HYPHY [89] accessed through the Datamonkey interface http://www.datamonkey.org. Mean numbers of nonsynonymous substitutions $(\mathrm{dN})$ and synonymous substitutions (dS) per site (ratio $\mathrm{dN} / \mathrm{dS}$ ) were estimated in the cox1 data using the fixed effect (two-rate FEL) method and basing estimates on a Neighbour-Joining tree under the HKY substitution model. We used a nominal alpha level of 0.1 .

To avoid any effect from compositional heterogeneity of sequences [90] on the phylogenetic reconstruction we separately tested each codon position of $\operatorname{cox} 1$ as well as 16S rRNA using the program TREE-PUZZLE 5.2 [91]. When we found indications for compositional heterogeneity we recoded the sequences into purines and pyrimidines and repeated the test.

\section{Morphological analysis}

The morphological characters considered are presented in Additional File 1. Our rationale in composing the character set was aiming at, first, a comprehensive capturing of variation at the species, subgenus and genus level, and, second, exclusion of any characters potentially distorting the phylogenetic reconstructions. We started from the complete set of character definitions of Janda et al. [38]. Pursuing our first aim, we applied 67 characters and their states exactly as described by [38], adapted - because analysis of our material revealed the necessity to do so - the definitions of character states, partly also concerning the number of character states, for another 16 characters, out of which 7 characters also were adapted in the character definitions themselves, and added 20 entirely new characters. Pursuing our second aim, we excluded from the set presented by [38] the three behavioural/ecological characters (among others the occurrence of social parasitism), and on the basis of information from $[1,2,13,54,55,63,64]$ we further excluded 37 morphological characters, including four of the new ones. The excluded characters were characters which we suspected to be functionally coupled with temporary social parasitism, either ( $i$ ) because of direct functional reasoning, or ( $i$ ) because they are known to be correlated with social parasitism in other ant genera which contain both parasitic and non-parasitic species. The characters excluded under (i) concerned the mandible, which is needed by parasitic Lasius queens to dismember host workers and strangle the host queen; the maxillary palp and the scape, which may be under selective pressure to be short and robust so as to escape damage by aggressive hosts in the initial stage of colony take-over; and the mesosoma size, because parasitic, i.e., dependently founding, queens need less tissue 
storage than independently founding queens. The characters excluded under (ii) concerned the length of hairs, which can be either extremely long or extremely short in parasites; the pubescence, which is absent in some parasites; the size of the head and the overall body, which both are frequently small in parasitic queens; and the shape of the petiole, which is frequently aberrant in parasites. We finally also excluded three characters for which we observed no variation in our material (their general lack of variation for the species analysed confirmed by a personal communication by B. Seifert, of April 2008). For details of how we composed our morphological data set including information on the provenance of characters and whether we excluded them, see Additional File 1. Overall, we included 64 morphological characters in our reconstructions; 35 of these concern adult workers, 18 adult queens, 23 adult males, and 2 worker larvae; 47 are binary and 17 are multi-state. To explore the effect of excluding characters, as we had done, on phylogenetic reconstructions, we also subjected the complete data set to reconstructions (but excluding invariant characters); this data set included 99 characters. We assessed any morphological data by analysis of voucher material housed in the National Science Museum, Tokyo, except the three characters concerning larval morphology. A total of 155 specimens were analysed. All multistate characters were treated as unordered.

\section{Phylogenetic reconstructions}

To select the best-fitting nucleotide substitution models for cox1 and 16S rRNA we used the hierarchical likelihood ratio test (hLRT) and the Akaike Information Criterion (AIC) implemented in the program MrModeltest 2.2 [92]. When sequence partitions had been recoded into purines and pyrimidines, models were adjusted to account for the two state character of the data. AIC and hLRT in one instance differed in the selection of models for the single DNA sequence data partitions (Table 2). AIC selected the more parameter rich model and we opted for this solution as erring on the side of overparameterisation is preferable over the opposite $[93,94]$.

For the morphological data the Markov $k(\mathrm{Mk})$ model [95] was applied both with $(+\Gamma)$ and without gamma-distributed rates of character change in separate MCMC runs. We used Bayes factors for model selection as they are established to provide good orientation tools in this [39] and calculated them as follows, using the outcomes of the single MCMC runs: $2 \mathrm{LnB}_{10}=2 \times$ (Harmonic Mean Ln likelihood for Mk - Harmonic Mean Ln likelihood for $\mathrm{Mk}+\Gamma$ ). In the interpretation of the yielded absolute value of 2.5 in favour of the $M \mathrm{k}+\Gamma$ model we followed published recommendations [96], on page 777, and consequently used the $\mathrm{Mk}+\Gamma$ model for all reconstructions.
Bayesian analysis using MCMC was performed with MrBayes 3.1.2 [97] on the individual data sets (cox1, $16 \mathrm{~S}$ $r R N A$, morphology) and the combined, concatenated data set ( $\operatorname{cox} 1$ plus $16 S$ rRNA plus morphology). We also analysed the combined, concatenated data set including those morphological characters suspected to be coupled with social parasitism. In addition, we analysed the concatenated molecular data ( $\operatorname{cox} 1$ plus $16 S \mathrm{rRNA}$ ) without any morphological data. Data partitions were established to allow model parameters to be separately estimated for all partitions and additionally for the single codon positions of $\operatorname{cox} 1$. 10,000,000 generations with a sample frequency set to 100 were run. As after 9,000,000 generations stationarity was achieved with average standard deviation of split frequencies in all cases constantly below 0.002 except the reconstruction with the W55 constraint for which it was 0.063 (Table 3), we always used the last 10,000 trees of each run to compute a majority rule consensus tree assigning posterior probabilities of tree topology. We also confirmed that true convergence had been reached and that the MCMC was sampling from the posterior distribution by repeating all runs three times and checking for congruence across the runs. All runs were performed using parallel versions of MrBayes, implemented on a SGI Origin 3800 under IRIX version $6.21 \mathrm{~m}$, of HPC, James Cook University. All MCMC runs achieved stationarity and detailed statistics on the runs are presented in Table 3. In the interpretation of the MCMC trees we followed previous authors $[94,98,99]$ to regard only nodes with node support of $\mathrm{p}>0.95$ as significantly supported in Bayesian analysis. We also applied this cutoff when comparing the MCMC trees based on the individual data sets and that based on the concatenated data.

We also performed MP analysis of the combined, concatenated data, as well as of the combined concatenated data adding those morphological characters suspected to be coupled with social parasitism. All MP analyses were unweighted and performed with PAUP* 4.0b10 [100] using the heuristic search algorithm with tree bisection reconnection branch swapping and 10 random stepwise additions. All characters were treated as unordered and polymorphic states were taken into account. Node support was calculated by 1,000 bootstrap replicates. In the interpretation of the MP trees, we applied the widely accepted node support threshold of $>70$ [67].

We deposited the aligned, concatenated data matrix with TreeBase (Study accession number S2136).

\section{Comparison with previous Lasius phylogenies}

To compare the subgenus relationships of W55, H98 and J04 directly with the new, Bayesian framework, we enforced the various topologies as constraints (Fig. 1) on our concatenated data. We then performed additional 
MCMC runs of our concatenated data under these constraints and compared the outcomes of the single MCMC runs using Bayes factors as given under morphological analyses. In extracting the topologies from the literature we proceeded as follows. For W55 we used the tree of "Fig. 2 " of [36] slightly modified. We adopted the position of Acanthomyops, explicitly treated as ingroup of Lasius in the tree, although Wilson did not formally treat Acanthomyops as a subgenus of Lasius in the taxonomic revision itself. We allocated Lasius sitkaensis, now treated as a junior synonym of L. pallitarsis, to Lasius sensu stricto. A similar situation pertains to Austrolasius: the subgenus had not yet been established in 1955, but the then only known species which today is treated under Austrolasius, L. carniolicus, was allocated to Chthonolasius and we accounted for this in our treatment of W55. For H98 we applied the node support threshold of $>70$ [67] to the Maximum Parsimony reconstruction presented in "Fig. 1" of [37], and we applied the same threshold for J04, to the Maximum Parsimony reconstruction presented in "Fig. 6" of [38].

\section{Posterior mapping analysis}

To estimate the probabilities of the possible ancestral states at each well supported node of the concatenated Bayesian topology we chose the Bayesian approach of posterior mapping $[61,62]$, using the program SIMMAP 1.0 [101] freely available online http://www.SIM MAP.com. In contrast to parsimony approaches to character mapping this is a probabilistic approach, which (i) does not assume that only a single change has occurred along any branch, and (ii) is not prone to underestimation of the variance in ancestral state assignments [101]. Further, the SIMMAP approach allows uncertainty in phylogenetic reconstruction. A single stochastic mapping was done per tree using the last 2,000 post-burnin trees of the 20,000 trees used to derive the consensus tree of Fig. 2 and the ancestral states were inferred for the consensus tree from the MrBayes analysis.

\section{Authors' contributions}

MM initiated the study, participated in its design and coordination, carried out the DNA sequencing work, performed the sequence alignment, and sampled the morphological characters. FMS participated in the design and coordination of the study, in the data analysis, in drafting a first version of the manuscript, and in revising it. TA helped with the design of the study. CS helped with the design of the study. RHC helped to design the data analysis and the format of the manuscript. BCS-S participated in the design and coordination of the study, in the data analysis, in drafting a first version of the manuscript, and in revising it. All authors read and approved the final version.

\section{Additional material}

\section{Additional File 1}

Definition and data matrix of morphological characters. L worker larva, $M$ adult male, $Q$ adult queen, $W$ adult worker. The characters are consecutively numbered in the definitions which equal the numbers used in the matrix. The numeric codes for the character state definitions are given in parentheses. If a species is polymorphic in character states, both states are given in parantheses. In the penultimate row, the corresponding character name of Janda et al. [38] is given and the following signs describe the relation to [38] concerning the definitions, "* "indicates that character and states are identical, $" * *$ indicates that the characters are identical but the states have been adapted, "***" that characters and states have been adapted, and $" * * * *$ "indicates new characters, not used in [38]. The letters in ultimate row indicate: "a" character used for reconstruction of new phylogenetic framework, " $b$ " character suspected to be functionally coupled with social parasitism or a behavioural/ecological character, " $c$ " invariant character. The samples of the matrix are identical with those given in Table 1. Subgenera are abbreviated as in Table 1. Click here for file

[http://www.biomedcentral.com/content/supplementary/14712148-8-237-S1.xls]

\section{Acknowledgements}

We thank A. Françoeur, N. Fujiwara, K. Hamaguti, Y. Ikeshita, T. Itino, F. Ito, Y. Kida, K. Kinomura, T. Kishimoto, T. Komatsu, S. Nagashima, K. Ogata, M. Ôhara, J.M. Raczkowski, C.A. Schmidt, T. Shimada, T. Toida for providing material. This work was performed at the molecular laboratory of Division of Mammals and Birds, National Science Museum, Tokyo, under supervision of I. Nishiumi, S. Hoshino and other staffs. For valuable information, we thank J. Felsenstein, K. Ogata, B. Seifert, and P.S. Ward. This project was partially supported by Grant-in-Aid of JSPS Postdoctoral Fellowship to MM. BCS and FMS were supported by the Austrian Science Fund [P-I72 19-B06, J2639-B I7, J2642-B 17]. RHC's work on evolutionary genetics is supported by the Australian Research Council [DP0665890]. We are also grateful to five anonymous referees and the Assistant Editor, E. Alexandersson, for constructive and inspiring suggestions.

\section{References}

I. Seifert B: Die Ameisen Mittel- und Nordeuropas Tauer: lutra Verlagsund Vertriebsgesellschaft; 2007.

2. Hölldobler B, Wilson EO: The Ants Cambridge, MA: The Belknap Press of Harvard University Press; 1990.

3. Akino T, Yamaoka R: Trail discrimination signal of Lasius japonicus (Hymenoptera: Formicidae). Chemoecology 2005, I 5:2 |-30.

4. Kern F, Klein RW, Janssen E, Bestmann H-J, Attygalle AB, Schäfer D, Maschwitz U: Mellein, a trail pheromone component of the ant Lasius fuliginosus. J Chem Ecol 1997, 23:779-792.

5. Wu J, Mori K: Synthesis of the enantiomers of 2,6-dimethyl-6helpten-I-ol, a mandibular gland secretion of the male ant Lasius niger. Agric Biol Chem 1991, 55:2667-2668.

6. Akino T, Yamaoka R: Evidence for volatile and contact signals of nestmate recognition in the black shining ant Lasius fuliginosus Latreille (Hymenoptera: Formicidae). Entomol Sci 2000, 3:|-8.

7. Morgan ED: Chemical sorcery for sociality: Exocrine secretions of ants (Hymenoptera: Formicidae). Myrmecol News 2008, I I :79-90.

8. Steiner FM, Schlick-Steiner BC, Moder K, Stauffer C, Arthofer W, Buschinger A, Espadaler X, Christian E, Einfinger K, Lorbeer E, Schafellner C, Ayasse M, Crozier RH: Abandoning aggression but maintaining self-nonself discrimination as a first stage in ant supercolony formation. Curr Biol 2007, I 7: 1903-1907. 
9. Bourke AFG, Franks NR: Social Evolution in Ants Princeton, NJ: Princeton University Press; 1995.

10. Crozier RH, Pamilo P: Evolution of Social Insect Colonies New York: Oxford University Press; 1996.

II. Fjerdingstad EJ, Gertsch PJ, Keller L: The relationship between multiple mating by queens, within-colony genetic variability and fitness in the ant Lasius niger. J Evol Biol 2003, 16:844-853.

12. Boomsma J], Have TM van der: Queen mating and paternity variation in the ant Lasius niger. Mol Ecol 1998, 7:1709-1718.

13. Buschinger A: Evolution of social parasitism in ants. Trends Ecol Evol 1986, I:155-160.

14. Bourke AFG, Franks NR: Alternative adaptations, sympatric speciation and the evolution of parasitic, inquiline ants. Biol J Linn Soc 199I, 43:157-178.

15. Ward PS: A new workerless social parasite in the ant genus Pseudomyrmex (Hymenoptera: Formicidae), with a discussion of the origin of social parasitism in ants. Syst Entomol 1996, 21:253-263.

16. Buschinger A: Sympatric speciation and radiative evolution of socially parasitic ants - heretic hypotheses and their factual background. Z zool Syst Evolut-forsch 1990, 28:24I-260.

17. Wilson EO: The Insect Societies Cambridge, MA: Harvard University Press; 1971.

18. Steiner FM, Schlick-Steiner BC, Konrad H, Moder K, Christian E, Seifert B, Crozier RH, Stauffer C, Buschinger A: No sympatric speciation here: Multiple data sources show that the ant Myrmica microrubra is not a separate species but an alternate reproductive morph of Myrmica rubra. I Evol Biol 2006, 19:777-787.

19. Emery C: Über den Ursprung der dulotischen, parasitischen und myrmekophilen Ameisen. Biol Centralbl 1909, 29:352-362.

20. Anderson KE, Linksvayer TA, Smith CR: The causes and consequences of genetic caste determination in ants (Hymenoptera: Formicidae). Myrmecol News 2008, I I:I I9-132.

21. Agosti D: A new inquiline ant (Hymenoptera: Formicidae) in Cataglyphis and its phylogenetic relationship. J Nat Hist 1994, 28:913-919.

22. Savolainen R, Vepsäläinen K: Sympatric speciation through intraspecific social parasitism. Proc Natl Acad Sci USA 2003, 100:7169-7174.

23. Beibl J, Buschinger A, Foitzik S, Heinze J: Phylogeny and phylogeography of the Mediterranean species of the parasitic ant genus Chalepoxenus and its Temnothorax hosts. Insect Soc 2007, 54:189-199.

24. Beibl J, Stuart RJ, Heinze J, Foitzik S: Six origins of slavery in formicoxenine ants. Insect Soc 2005, 52:29|-297.

25. Sumner S, Aanen DK, Delabie J, Boomsma JJ: The evolution of social parasitism in Acromyrmex leaf-cutting ants: a test of Emery's rule. Insect Soc 2004, 5 I:37-42.

26. Sanetra M, Buschinger A: Phylogenetic relationships among social parasites and their hosts in the ant tribe Tetramoriini (Hymenoptera: Formicidae). Eur J Entomol 2000, 97:95-II7.

27. Baur A, Sanetra M, Chalwatzis N, Buschinger A, Zimmermann FK: Sequence comparisons of the internal transcribed spacer region of ribosomal genes support close relationships between parasitic ants and their respective host species (Hymenoptera: Formicidae). Insect Soc 1996, 43:53-67.

28. Mueller UG, Gerardo NM, Aanen DK, Six DL, Schultz TR: The evolution of agriculture in insects. Annu Rev Ecol Evol Syst 2005 36:563-595.

29. Maschwitz U, Hölldobler B: Der Kartonnestbau bei Lasius fuliginosus Latr. (Hym., Formicidae). Z vergl Physiol 1970, 66: I76-189.

30. Elliott JSB: Fungi in the nests of ants. Trans Br Mycol Soc 1915 5:138-142.

31. Fresenius JBGW: Beiträge zur Mykologie 2 Frankfurt: HL Brönner Verlag; 1852.

32. Lagerheim G: Ueber Lasius fuliginosus (Latr.) und seine Pilzzucht. Entomol Tidskr Arg 1900, 2 1:2-29.

33. Schlick-Steiner BC, Steiner FM, Konrad H, Seifert B, Christian E, Moder K, Stauffer C, Crozier RH: Specificity and transmission mosaic of ant nest wall fungi. Proc Natl Acad Sci USA 2008 105:941-944.

34. Mikheyev AS, Mueller UG, Abbot P: Cryptic sex and many-to-one coevolution in the fungus-growing ant symbiosis. Proc Natl Acad Sci USA 2006, 103:10702-10706.

35. Schultz TR, Brady SG: Major evolutionary transitions in ant agriculture. Proc Natl Acad Sci USA 2008, 105:5435-5440.
36. Wilson EO: A monographic revision of the ant genus Lasius. Bull Mus Comp Zool 1955, I I 3:3-205.

37. Hasegawa E: Phylogeny and host-parasite relationships in social parasitism in Lasius ants. Entomol Sci 1998, I: I33-135.

38. Janda M, Folkova D, Zrzavy J: Phylogeny of Lasius ants based on mitochondrial DNA and morphology, and the evolution of social parasitism in the Lasiini (Hymenoptera: Formicidae). Mol Phylogenet Evol 2004, 33:595-6I4.

39. Nylander JAA, Ronquist F, Huelsenbeck JP, Nieves-Aldrey JL: Bayesian phylogenetic analysis of combined data. Syst Biol 2004, 53:47-67.

40. Ronquist F: Bayesian inference of character evolution. Trends Ecol Evol 2004, 19:475-48।

41. Ward PS, Downie DA: The ant subfamily Pseudomyrmecinae (Hymenoptera: Formicidae): phylogeny and evolution of bigeyed arboreal ants. Syst Entomol 2005, 30:310-335.

42. Brady SG, Schultz TR, Fisher BL, Ward PS: Evaluating alternative hypotheses for the early evolution and diversification of ants. Proc Natl Acad Sci USA 2006, 103:18172-18177.

43. Wetterer JK, Schultz TR, Meier R: Phylogeny of fungus-growing ants (Tribe Attini) based on mtDNA sequence and morphology. Mol Phylogenet Evol 1998, 9:42-47.

44. Lucas C, Fresneau D, Kolmer K, Heinze J, Delabie JHC, Pho DB: A multidisciplinary approach to discriminating different taxa in the species complex Pachycondyla villosa (Formicidae). Biol J Linn Soc 2002, 75:249-259.

45. Ward PS, Brady SG: Phylogeny and biogeography of the ant subfamily Myrmeciinae (Hymenoptera: Formicidae). Invertebr Syst 2003, 17:36I-386.

46. Knaden M, Tinaut A, Cerda X, Wehner S, Wehner R: Phylogeny of three parapatric species of desert ants, Cataglyphis bicolor, C. viatica and C. savignyi: a comparison of mitochondrial DNA, nuclear DNA, and morphological data. Zoology 2005, 108:169-177.

47. Schlick-Steiner BC, Steiner FM, Moder K, Seifert B, Sanetra M, Dyreson $E$, Stauffer $C$, Christian E: A multidisciplinary approach reveals cryptic diversity in western Palearctic Tetramorium ants (Hymenoptera: Formicidae). Mol Phylogenet Evol 2006, 40:259-273.

48. Brady SG: Evolution of the army ant syndrome: The origin and long-term evolutionary stasis of a complex of behavioral and reproductive adaptations. Proc Natl Acad Sci USA 2003, 100:6576-6579.

49. Moreau C, Bell CD, Vila R, Archibald SB, Pierce NE: Phylogeny of the ants: Diversification in the age of angiosperms. Science 2006, 3 I 2: I0I- 104

50. Kronauer DJC, Schöning C, Vilhelmsen LB, Boomsma JJ: A molecular phylogeny of Dorylus army ants provides evidence for multiple evolutionary transitions in foraging niche. BMC Evol Biol 2007, 7:56.

51. Philippe $\mathrm{H}$, Forterre $\mathrm{P}$ : The rooting of the universal tree of life is not reliable. J Mol Evol 1999, 49:509-523.

52. Zink RM, Drovetski SV, Rohwer S: Selective neutrality of mitochondrial ND2 sequences, phylogeography and species limits in Sitta europaea. Mol Phylogenet Evol 2006, 40:679-686.

53. Radwan J, Kawalko A, Wojcik JM, Babik W: MHC-DRB3 variation in a free-living population of the European bison, Bison bonasus. Mol Ecol 2007, 16:53 I-540.

54. Seifert B, Buschinger A: Pleometrotische Koloniegründung von Lasius meridionalis (Bondroit, 1920) bei Lasius paralienus Seifert, 1992, mit Bemerkungen über morphologische und ethologische Anpassungen an die sozialparasitische Koloniegründung (Hymenoptera: Formicidae). Myrmecologische Nachrichten 200।, 4: II-25.

55. Wilson EO: Leptothorax duloticus and the beginnings of slavery in ants. Evolution 1975, 29:108-119.

56. Jenner R: Presumed primitive until proving derived: appreciating evolutionary loss. The Systematist 2004, 23:12-16.

57. Sorensen MV, Giribet G: A modern approach to rotiferan phylogeny: Combining morphological and molecular data. Mol Phylogenet Evol 2006, 40:585-608.

58. Grandcolas P, Deleporte P, Desutter-Grandcolas L, Daugeron C: As many characters as possible should be included in the cladistic analysis. Cladistics 200I, 17:104-1 I0. 
59. Belfiore NM, Liu L, Moritz C: Multilocus phylogenetics of a rapid radiation in the genus Thomomys (Rodentia: Geomyidae). Syst Biol 2008, 57:294-310.

60. Kubatko LS, Degnan JH: Inconsistency of phylogenetic estimates from concatenated data under coalescence. Syst Biol 2007, 56:17-24.

61. Schultz TR, Churchill GA: The role of subjectivity in reconstructing ancestral character states: A Bayesian approach to unknown rates, states, and transformation asymmetries. Syst Biol 1999, 48:65I-664.

62. Huelsenbeck JP, Nielsen R, Bollback JP: Stochastic mapping of morphological characters. Syst Biol 2003, 52:131-158.

63. Stille M: Queen/worker thorax volume ratios and nest-founding strategies in ants. Oecologia 1996, 105:87-93.

64. Keller L, Passera L: Size and fat content of gynes in relation to the mode of colony founding in ants (Hymenoptera; Formicidae). Oecologia 1989, 80:236-240.

65. Hurst GDD, Jiggins FM: Problems with mitochondrial DNA as a marker in population, phylogeographic and phylogenetic studies: the effects of inherited symbionts. Proc $R$ Soc $B 2005$, 272: I525-I534.

66. Ward PS: A synoptic review of the ants of California (Hymenoptera: Formicidae). Zootaxa 2005, 936: I-68.

67. Hillis DM, Bull Jj: An empirical test of bootstrapping as a method for assessing confidence in phylogenetic analysis. Syst Biol 1993, 42: 182-192.

68. Felsenstein J: Taking variation of evolutionary rates between sites into account in inferring phylogenies. J Mol Evol 200I, 53:447-455.

69. Harris SR, Pisani D, Gower DJ, Wilkinson M: Investigating stagnation in morphological phylogenetics using consensus data. Syst Biol 2007, 56:125-129.

70. Bolton B, Alpert G, Ward PS, Naskrecki P: Bolton's Catalogue of Ants of the World: 1758-2005 Cambridge, MA: Harvard University Press; 2007.

7I. Wilson EO: Tropical social parasites in the ant genus Pheidole, with an analysis of the anatomical parasitic syndrome (Hymenoptera: Formicidae). Insect Soc 1984, 31:316-334.

72. Baur A, Chalwatzis N, Buschinger A, Zimmermann FK: Mitochondrial DNA sequences reveal close relationships between social parasitic ants and their host species. Curr Genet 1995, 28:242-247.

73. Steiner FM, Schlick-Steiner BC, Schödl S, Espadaler X, Seifert B, Christian E, Stauffer C: Phylogeny and bionomics of Lasius austriacus (Hymenoptera, Formicidae). Insect Soc 2004, 5 I:24-29.

74. Pontin AJ: Population stabilization and competition between the ants Lasius flavus (F.) and L. niger (L.). J Anim Ecol 1961, 30:47-54.

75. Mueller UG, Schultz TR, Currie CR, Adams RMM, Malloch D: The origin of the attine ant-fungus mutualism. $Q \operatorname{Rev} B i o l 200 \mathrm{I}$ 76:169-197.

76. Savolainen R: Phylogenetic relationships of Lasius, and the evolution of parasitic colony founding. In XIV International Congress of IUSSI. The Golden Jubilee Proceedings. 27 July - 3 August 2002, Hokkaido University, Sapporo, Japan IUSSI, Sapporo; 2002:159.

77. Seifert B: A taxonomic revision of the Palaearctic members of the ant subgenus Lasius s. str. (Hymenoptera: Formicidae). Abh Ber Naturkundemus Görlitz 1992, 66: I-67.

78. Umphrey G]: Sperm parasitism in ants: selection for interspecific mating and hybridization. Ecology 2006, 87:2148-2159.

79. Seifert B: Social cleptogamy in the ant subgenus Chthonolasius Ruzsky, 1912 - survival as a minority. Abh Ber Naturkundemus Görlitz 2006, 77:251-276.

80. Hasegawa E, Crozier RH: Phylogenetic relationships among species groups of the ant genus Myrmecia. Mol Phylogenet Evol 2006, 38:575-582.

81. Wing MW: Taxonomic revision of the Nearctic ant genus Acanthomyops (Hymenoptera: Formicidae). Mem Cornell Univ Agr Exp Stn 1968, 405:1-173.

82. Yamauchi $\mathrm{K}$, Hayashida $\mathrm{K}$ : Taxonomic studies on the genus Lasius in Hokkaido, with ethological and ecological notes. 2. The subgenus Lasius. J Fac Sci Hokkaido Univ Ser 6, Zool 1970, 17:501-519.

83. Seifert $B:$ A revision of the European species of the ant subgenus Chthonolasius (Insecta, Hymenoptera, Formicidae). Entomol Abh Staatl Mus Tierkd Dres 1988, 5 I:143-180.
84. Johnson KP, Yoshizawa K, Smith VS: Multiple origins of parasitism in lice. Proc $R$ Soc London (B) 2004, 27 I: I77I- 1776.

85. Palumbi SR, Martin A, Romano S, McMillan WO, Stice L, Grabowski G: The Simple Fool's Guide to PCR, Version 2.0. Privately published University of Hawaii; 199I.

86. Thompson JD, Gibson TJ, Plewniak F, Jeanmougin F, Higgins DG: The CLUSTAL $X$ windows interface: flexible strategies for multiple sequence alignment aided by quality analysis tools. Nucleic Acids Res 1997, 25:4876-4882.

87. Xia X, Xie Z: DAMBE: Data analysis in molecular biology and evolution. J Heredity 200I, 92:37I-373.

88. Xia X, Xie Z, Salemi M, Chen L, Wang Y: An index of substitution saturation and its application. Mol Phylogenet Evol 2003, 26:I-7.

89. Kosakovsky Pond SL, Frost SDW, Muse SV: Datamonkey: rapid detection of selective pressure on individual sites of codon alignments. Bioinformatics 2005, 21:2531-2533.

90. Jermiin LS, Ho SYW, Ababneh F, Robinson J, Larkum AWD: The biasing effect of compositional heterogeneity on phylogenetic estimates may be underestimated. Syst Biol 2004, 53:638-643.

91. Schmidt HA, Strimmer K, Vingron M, von Haeseler A: TREEPUZZLE: maximum likelihood phylogenetic analysis using quartets and parallel computing. Bioinformatics 2002, 18:502-504.

92. Lemmon AR, Moriarty EC: The importance of proper model assumption in Bayesian phylogenetics. Syst Biol 2004, 53:267-277.

93. Nylander JAA: MrModeltest v2. Program distributed by the author Evolutionary Biology Centre, Uppsala University; 2004.

94. Huelsenbeck JP, Rannala B: Frequentist properties of Bayesian posterior probabilities of phylogenetic trees under simple and complex substitution models. Syst Biol 2004, 53:904-9|3.

95. Lewis PO: A likelihood approach to estimating phylogeny from discrete morphological character data. Syst Biol 2001 , 50:913-925.

96. Kass RE, Raftery AE: Bayes factors. J Am Stat Assoc 1995, 90:773-795.

97. Ronquist F, Huelsenbeck JP: MrBayes 3: Bayesian phylogenetic inference under mixed models. Bioinformatics 2003, 19:1572-1574.

98. Wilcox TP, ZwickI DJ, Heath TA, Hillis DM: Phylogenetic relationships of the dwarf boas and a comparison of Bayesian and bootstrap measures of phylogenetic support. Mol Phylogenet Evol 2002, 25:36I-37I.

99. Hillis DM, Bull Jj: An empirical test of bootstrapping as a method for assessing confidence in phylogenetic analysis. Syst Biol 1993, 42: 182-192.

100. Swofford DL: PAUP*: Phylogenetic analysis using parsimony (*and other methods), ver. 4.0b4a Sunderland, MA: Sinauer; 2003.

10I. Bollback JP: SIMMAP: stochastic character mapping of discrete traits on phylogenies. BMC Bioinformatics 2006, 7:88.

Publish with Bio Med Central and every scientist can read your work free of charge

"BioMed Central will be the most significant development for disseminating the results of biomedical research in our lifetime. "

Sir Paul Nurse, Cancer Research UK

Your research papers will be:

- available free of charge to the entire biomedical community

- peer reviewed and published immediately upon acceptance

- cited in PubMed and archived on PubMed Central

- yours - you keep the copyright
BioMedcentral 